\title{
DEVELOPMENT WORK IN ARITHMETIC.
}

\section{By Myrtie Collier, \\ California State Normal School, Los Angeles.}

Arithmetic should be taught in such a way that the number facts learned may be usable in the life of the child, and also usable in the everyday life of the individual after leaving school. To secure this result in our school work two factors of arithmetic need special emphasis, namely:

1. The removal of all mystery in the fundamental operations and principles of number relations.

2. The application of the number facts through practical problems to bring the child into vital touch with actual business and industry.

It is the purpose of this article to discuss the first factor only.

The principles of arithmetic should be developed in such a way that all mystery in the mechanical operation be removed. In most, if not in all cases, this can best be done by the inductive method. Here we may use the five formal steps of the Herbatian lesson plan, namely, preparation, presentation, comparison, generalization, and application. The first step should be the need on the part of the pupil for the principle. This should be a childish need, or one within the experiences of the child, but it is the duty of the teacher to create this need. Feeling the need for the principle the pupil has the aim. For example, we have come to the time when we want to teach formal multiplication of fractions. We may have in some of the pupils' work measurements involving $\frac{3}{4}$ ". This measurement is used a number of times, say five. The question is how many inches in all. From what the child already knows he will add thus, $\frac{3 \prime \prime}{4}+\frac{3}{4}+13^{\prime \prime}+\frac{3}{4}+13^{\prime \prime}=15 / 4=3 \frac{3}{4}$. Since the addends are all alike how else may we secure the results? The child will know from his previous work in integers that it is by multiplying.

The second step is the securing of data from which the principle may be derived, for no one can reason without data. Here again it is the function of the teacher to supply this data. To continue our illustration of the multiplication of fractions by an integer several problems are given similar to the first, as,

$$
\begin{aligned}
& 4 x^{2} / 3=? \\
& 4 x^{3} / 5=? \\
& 5 x^{2} / 7=? \\
& 2 x^{3} / 4=?
\end{aligned}
$$


each problem being solved by the pupil as follows:

$$
\begin{array}{lll}
4 \mathrm{x}^{2} / 3=? & 2 / 3+2 / 3+2 / 3+2 / 3 & =8 / 3 . \\
4 \mathrm{x}^{3} / 5=? & 3 / 5+3 / 5+3 / 5+3 / 5 & =12 / 5 . \\
5 \mathrm{x}^{2} / 7=? & 2 / 7+2 / 7+2 / 7+2 / 7+2 / 7 & =10 / 7 . \\
2 \mathrm{x}^{3} / 4=? & 3 / 4+3 / 4 & =6 / 4 .
\end{array}
$$

The question mark is removed and the product placed after the equality sign.

The third step leads to a comparison of results by skilful questioning on the part of the teacher, as, what is the relation of the numerator of your product and the numerator of your multiplicand in the first? the second? and so on through. How then may we obtain the same product other than by adding? With all the concrete problems before them the pupils will DISCOVER that the same result may be obtained by multiplying the numerator of the fraction by the whole number and writing the result over the denominator. This is our fourth step or generalization. At once we should test the principle suggested by the students. A good method is to let each pupil make his own problem, solve it by applying the new principle and then check his result by adding thus, $5 \times x^{4} / 7=20 / 7$.

$$
\text { Check } \quad 4 / 7+4 / 7+4 / 7+4 / 7+4 / 7 \quad=20 / 7 \text {. }
$$

Since the rule holds good for so many problems we will consider it correct for all problems. Lastly comes the application or drill until the new principle becomes a fixed habit of control.

The fourth step is deductive reasoning, but quite as necessary as the preceding steps. In fact induction and deduction are not distinct in the sense that sometimes we use the one and sometimes the other. Charters says, "They are complementary to each other." We are emphasizing the inductive method when we lead from the particular to the general, and the deductive method when we lead from the general to the particular. After the principle is established inductively with small numbers it should be used deductively with larger numbers, if larger numbers are used at all.

To be sure the principles of arithmetic may be taught either inductively or deductively as a mere learned fact. Thorndike says, "Indeed the mere mechanical learning of the procedure may seem to many the most economical method. It should, however, be noted that such mechanical learning is really inductive, the generalization coming after much drill and being in the form, 'This procedure is right because it always gives the right answer,' the

1 Methods of Teaching. 
teacher's word or the answer-key being the means of verification.",

In development work free mental activity should always be aimed at, but the teacher should guide the pupils by questioning in such a way that time will not be wasted in random guessing, or in wandering from the aim.

After the principle has been established by the pupils they should not be expected to repeat and repeat it in verbal form, but should be led to express themselves in number form. If a pupil is able to multiply a fraction by a whole number, and has removed all mystery as to the mechanical process, why should he be expected to repeat the principle continually, or to tell how it was derived? The thing to do is TO USE IT until the process becomes automatic.

Each new principle or operation should not be learned as a separate, unrelated operation. The teacher should know her pupils thoroughly in order that she may draw upon their past experiences in developing the new work. For example, they know that multiplication of integers is only a short process of addition where the addends are all alike, and should be led to see that this fact holds true in fractions. The only new thing here is the handling of the numerator. Our teaching process thus becomes a leading from the old to the new. Mr. Courtis says, "It seems practically certain that in the present state of our afithmetic teaching each operation and each part or division of a topic is learned by the child as a separate, unrelated activity. There is no co-ordination, no welding of separate parts into one science of number, no appreciation of the meaning and purpose of arithmetic as a whole. Accordingly the incidental emphasis of the teacher on one topic or another, due to the varying mentalities of the different classes of the same grade, leaves a lasting bias toward skill in one operation or another."' There is nothing that will remove this save a logical arrangement and a psychological development of the principles of arithmetic.

The inductive method of teaching necessitates concrete work, but concrete work does not necessarily mean that objects present to the senses be used. Object work is good, and in many cases indispensable, but it is often abused by its continued use after its usefulness has passed. In the use of objects care must be taken in selecting and varying the objects so that the object ceases to 
be the important thing leaving the number relation in the memory.

To summarize, it may be said there are five distinet advantages of this method over the deductive method, or the giving of the rule by the teacher or taking it from the book.

The first and most important advantage is that the work becomes a joy through the creative activity of the child. In speaking of this Suzzallo says, "When he (the child) has found the fact he has already learned it."

In the second place he is led to an independent feeling instead of a dependent one. He no longer feels the need of the teacher as a crutch.

In the third place he is more able to apply the number facts to the arithmetical problems of life, because he understands the principle, and thereby understands the use to which it may be put.

In the fourth place he is more able to re-establish a forgotten principle. Since he has reasoned the principle out once he may be able to reorganize his known facts and thus to reason the organization out again.

In the fifth place he is more able to make "short cuts" in handling numbers. If he is given the principle usually he has to be given the short cut also as a separate and distinct operation.

4 The Teaching of Primary Arithmetic.

\section{A BULBOUS EPIPHYTE.}

Epiphytes are plants which grow upon others without depending upon them for food. In temperate regions, many mosses, lichens and a few ferms are epiphytes, but it is not until the tropics are reached that we find flowering plants of this nature. In the tropical rain forest, however, there are numerous flowering plants that have become epiphytes, notably the orchids, the pitcher plants, and the plants of the pineapple family. The position of these plants on the trunks and branches of trees, prevents their absorbing water as needed, as plants rooted in the soil are able to do, and they are, therefore, obliged to keep pretty close to regions where the rainfall is frequent and abundant. As a rule the epiphytes possess cisterns or other devices for storing the precious moisture against a time of drouth. In a country where it is always summer there is no need for plants to store food and, as might be inferred, plants with bulbs, corms, or thickened rootstocks are exceedingly rare among epiphytes. A few species have bulbous parts, ustally stems, but these are for the storage of water, not food. A remarkable exception to this condition is found in a new plant reported from South Africa in which there is a bulb of the conventional style. The plant belongs to the Amaryllidaceae and has been named Cyrtanthus epiphyticus. It is said to be the first Amaryllidaceous plant recorded as an epiphyte. The plant grows with its bulb embedded in the moss on the trunks and branches of a species of yellow wood (Podocarpus).-American Botanist. 